\title{
In vitro SUSCEPTIBILITY TESTING OF DERMATOPHYTES ISOLATED FROM PEDIATRIC CASES IN NIGERIA AGAINST FIVE ANTIFUNGALS
}

\author{
E.I. NWEZE(1, 2), C.C. OGBONNA(3) \& J.I. OKAFOR(1)
}

\begin{abstract}
SUMMARY
The antifungal activities of itraconazole, ketoconazole, fluconazole, terbinafine and griseofulvin were tested by broth microdilution methods against 71 isolates of dermatophytes isolated from Nigerian children. Most drugs were very active against all the dermatophytes and the MIC 90 ranged from 0.03 to $8.0 \mu \mathrm{g} / \mathrm{mL}$. This appears to be the first documented data on the antifungal susceptibility testing of isolates of dermatophytes from Nigerian children.
\end{abstract}

KEYWORDS: Antifungal susceptibility testing; Dermatophytes; Children; Nigeria.

\section{INTRODUCTION}

Dermatophytosis is a common cutaneous fungal disease caused by species belonging to the genera Trichophyton, Microsporum and Epidermophyton. Several therapeutic regimens are reported to have activity in these fungi and are therefore being used in treating it ${ }^{9,17}$. Although in the last few years, there has been a steady introduction of new drugs by either modification of pre-existing or entirely new chemical classes of antimycotics, there has also been an increased interest in clinically relevant susceptibility testing ${ }^{16}$. This has become necessary due to a considerable increase in the prevalence of dermatophytoses all over the world especially in underdeveloped countries such as Nigeriaa ${ }^{2,8,13,14}$ among the elderly and in immunocompromised patients ${ }^{6}$. It is known that there is lack of data on the antifungal susceptibility of dermatophytes in African countries, such as Nigeria, where the occurrence of dermatophytosis is endemic. Expansion of information on in vitro susceptibility testing of dermatophytes will provide data that will help in developing or selecting drug regimens ${ }^{10}$. In addition, the various cases of imported dermatophyte infection across different countries and their variable response to the antifungals make exchange of information on susceptibility data across different countries necessary. Therefore, the purpose of the present work was to carry out antifungal susceptibility testing on clinical isolates from pediatric cases of dermatophytosis.

\section{MATERIALS AND METHODS}

Test isolates: A total of seventy-one isolates of dermatophytes were evaluated. Out of this 27 were Trichophyton tonsurans, 15 were Trichophyton soudanense, seven were Trichophyton violaceum, five were Trichophyton rubrum, four were Trichophyton verrucosum, nine were Trichophyton mentagrophytes, three were Trichophyton schoenlenii and two each of Epidermophyton flocossum and Microsporum audounii. Three American Typed Culture Collections (ATCC) quality control organisms were used: Candida parasilopsis ATCC 22019, Trichophyton mentagrophytes (ATCC 40004) and Candida krusei ATCC 6258. These dermatophytes were mainly isolates from different body sites collected during previous investigational study ${ }^{13,14}$. The cultures were maintained on Saboraud dextrose agar slants supplemented with cycloheximide, chloramphenicol and genticin (SAB-CCG). Freshly growing cultures on SAB-CCG slants were transferred to oatmeal agar slants two weeks prior to the study to enhance conidial production as proposed previously ${ }^{12}$.

Antifungal agents: Five antifungal agents were used, itraconazole (ITR) and ketoconazole (KET) (Jansen), fluconazole (FLU) (Pfizer), terbinafine (TER), (Novartis) and griseofulvin (GRI) (Schering Plough). Fluconazole and ketoconazole were dissolved in sterile distilled water while the rest were dissolved in $100 \%$ dimethylsulphuroxide (SigmaAldrich). They were subsequently prepared as stock solutions and stored at appropriate temperature.

In vitro tests for susceptibility: For susceptibility testing, the drugs were diluted in RPMI 1640 (Sigma-Aldrich) with L-glutamine but without sodium bicarbonate and buffered at PH 7 with MOPS.

Preparation of inocula: The inocula were prepared according to NORRIS et al. ${ }^{12}$. Briefly, conidial suspensions of dermatophytes prepared from seven to fourteen day old culture grown on oatmeal cereal agar slants were made. The slants were flooded with $0.85 \%$ sterile saline and swabbed with a cotton wool tip applicator. The resulting mixture of conidia and hyphal particles were subsequently 


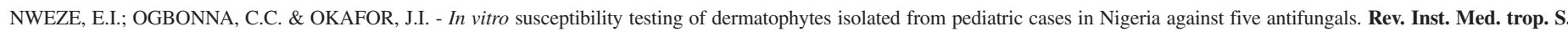
Paulo, 49(5): 293-295, 2007.

transferred to a sterile tube. After settling for about 15-20 minutes, the upper layer (about $2 \mathrm{~mL}$ ) of the suspension was removed and adjusted for $80-85 \%$ transmission using a colorimeter. This corresponds to an inoculum of $1-5 \times 10^{6} \mathrm{CFU} / \mathrm{mL}$. The inoculum was adjusted to $5 \mathrm{~mL}$ with saline $(0.85 \%)$ and diluted further in RPMI 1640 to achieve a final concentration of $2-5 \times 10^{3} \mathrm{CFU} / \mathrm{mL}$.

Testing procedure: The procedure followed CLSI guideline M 27- $\mathrm{P}^{11}$, Micro dilution plates were set up and each test plate had two drug free growth controls, one with the media alone (growth control) and the other with media containing an equivalent amount of solvent used to dissolve the antifungal drug (solvent control). The plates (two for each) were incubated at $30{ }^{\circ} \mathrm{C}$ and $35{ }^{\circ} \mathrm{C}$ respectively and read visually after four and five days of incubation. Growth was normally checked after $48 \mathrm{~h}$ post inoculation. Endpoint determinations were made by visually comparing the growth in the wells containing the drug with the growth in the solvent control well. MIC ranges were obtained for each species-drugs combination tested. To facilitate comparisons of the activities of the drugs, the MIC was reported as the concentration at which 50\% (MIC50) and 90\% (MIC90) of the isolates were inhibited.

\section{RESULTS}

The in vitro susceptibilities of 71 isolates of dermatophytes to terbinafine, itraconazole, ketoconazole, fluconazole and griseofulvin are summarized in Table 1. The MIC90 and MIC50 are also shown. The data are presented as MIC ranges and, where appropriate, as the drug concentrations required to inhibit 50 and $90 \%$ of the isolate of each species (MIC90 and MIC50 respectively) All the 71 isolates of dermatophytes tested were susceptible to the five antifungal drugs used in the study. The MIC of all the quality control strains used were within established ranges (data not shown) ${ }^{1}$.

Although detectable growths were noticed after four days of incubation in some cases, majority of the isolates had pronounced growth after five days. We observed no major differences in incubating at 30 or $35^{\circ} \mathrm{C}$, but our result reflect readings recorded at $35^{\circ} \mathrm{C}$. However, no resistance was recorded among all the isolates. The isolates were less susceptible for griseofulvin and fluconazole with MICs ranging from $0.125-16.0$ and $0.25-64 \mu \mathrm{g} / \mathrm{mL}$. The MIC90 range for them respectively is between $2.0-8.0 \mu \mathrm{g} / \mathrm{mL}$ for griseofulvin and $4.0-16.0$ $\mu \mathrm{g} / \mathrm{mL}$ for fluconazole. Terbinafine was the most effective drug against all isolates of dermatophytes since the MIC90 range was between 0.01 - $0.07 \mu \mathrm{g} / \mathrm{mL}$. The order of in vitro activity is therefore terbinafine $>$ itraconazole $>$ ketoconazole $>$ griseofulvin $>$ fluconazole.

\section{DISCUSSION}

Monitoring antimicrobial resistance is useful because apart from tracking and detection of resistance trends by microorganisms, it also gives clues to emerging threats of new resistance. This serves among other things, in assessing interventional efforts and empirical treatments recommendations ${ }^{15}$. In the past, several authors have performed in vitro susceptibility tests on various strains of dermatophytes ${ }^{6,10,12}$. However, there is a scarcity of data on susceptibility studies of isolates from the West African sub region like Nigeria ${ }^{13,14}$. Therefore, this is the first largescale in vitro susceptibility testing of dermatophytes obtained from
Table 1

MICs of the five drugs against seventy-one clinical isolates of dermatophytes. MIC $(\mu \mathrm{g} / \mathrm{mL})$

\begin{tabular}{|c|c|c|c|c|}
\hline Species $\left(\mathrm{n}^{\mathrm{A}}\right)$ & $\begin{array}{l}\text { Antifungal } \\
\text { drug }\end{array}$ & Range & $\mathrm{MIC} 0^{\mathrm{B}}$ & MIC90 \\
\hline \multirow[t]{5}{*}{ T. tonsurans $(25)$} & TER & $0.007-0.125$ & 0.07 & 0.125 \\
\hline & ITR & $0.06-0.5000$ & 0.01 & 0.03 \\
\hline & KET & $0.125-1.00$ & 0.125 & 0.25 \\
\hline & FLU & $0.25-16.00$ & 1.00 & 4.00 \\
\hline & GRI & $0.50-16.00$ & 2.00 & 8.00 \\
\hline \multirow[t]{5}{*}{ T. soundanense(15) } & TER & $0.01-0.25$ & 0.01 & 0.06 \\
\hline & ITR & $0.03-0.125$ & 0.03 & 0.125 \\
\hline & KET & $1.00-16.00$ & 1.00 & 2.00 \\
\hline & FLU & $8.00-32.00$ & 8.00 & 16.00 \\
\hline & GRI & $2.00-16.00$ & 2.00 & 8.00 \\
\hline T. mentagrophytes & TER & $0.007-0.500$ & 0.07 & - \\
\hline \multirow[t]{4}{*}{ (9) } & ITR & $0.01-4.00$ & 0.01 & - \\
\hline & KET & $0.06-4.00$ & 0.05 & - \\
\hline & FLU & $0.06-64.00$ & 2.00 & - \\
\hline & GRI & $0.125-4.00$ & 0.50 & - \\
\hline \multirow[t]{5}{*}{ T. violaceum (7) } & TER & $0.007-0.125$ & 0.01 & - \\
\hline & ITR & $0.01-1.00$ & 0.01 & - \\
\hline & KET & $0.03-0.25$ & 0.25 & - \\
\hline & FLU & $1.00-8.00$ & 1.00 & - \\
\hline & GRI & $0.25-8.00$ & 0.50 & - \\
\hline \multirow{5}{*}{ T. verrucosum(4) } & TER & $0.007-0.125$ & 0.007 & - \\
\hline & ITR & $0.125-1.00$ & 0.125 & - \\
\hline & KET & $1.00-16.00$ & 2.00 & - \\
\hline & FLU & $4.00-16.00$ & 4.00 & - \\
\hline & GRI & $0.50-4.00$ & 4.00 & - \\
\hline \multirow[t]{4}{*}{ T. rubrum (5) } & TER & $0.03-0.25$ & 0.007 & - \\
\hline & ITR & $0.03-1.00$ & 0.03 & - \\
\hline & KET & $0.125-4.00$ & 0.125 & - \\
\hline & FLU & $1.00-8.00$ & 2.00 & - \\
\hline \multirow[t]{5}{*}{ T. schoenleinii(3) } & TER & 0.007 & - & - \\
\hline & ITR & $0.01-0.50$ & - & - \\
\hline & KET & $0.06-0.125$ & - & - \\
\hline & FLU & $>16$ & - & - \\
\hline & GRI & $4.00-16.00$ & - & - \\
\hline \multirow[t]{5}{*}{ M. audouinii(2) } & TER & 0.01 & - & - \\
\hline & ITR & $0.01-0.125$ & - & - \\
\hline & KET & $0.01-0.50$ & - & - \\
\hline & FLU & $0.50-2.00$ & - & - \\
\hline & GRI & $0.25-1.00$ & - & - \\
\hline \multirow[t]{5}{*}{ E. floccosum(2) } & TER & $0.01-0.125$ & - & - \\
\hline & ITR & $0.01-0.50$ & - & - \\
\hline & KET & $0.01-1.00$ & - & - \\
\hline & FLU & $0.50-2.00$ & - & - \\
\hline & GRI & $1.00-2.00$ & - & - \\
\hline
\end{tabular}

$\mathrm{n}^{\mathrm{A}}$ : number of isolates tested; ${ }^{\mathrm{B}}$ : MIC for $50 \%$ of the isolates tested; -: MIC 50 and 90 were not determined because of their small sample number. 
Nigeria pediatric patients, against a wide range of commonly used antifungals in our country. Like we have noted above, we observed no major differences in the MIC endpoints by incubating at $30{ }^{\circ} \mathrm{C}$ or $35^{\circ} \mathrm{C}$. Information available in the literature from other authors ${ }^{10,15,16}$ indicated that four days of incubation were sufficient to observe noticeable growth in the control wells. We therefore recorded our MIC values after four days of incubation. However, our results disagreed from SANTOS \& HAMADA $^{18}$ and from FERNANDEZ-TORRES et al. ${ }^{5}$. In another study FERNANDEZ-TORRES et al. ${ }^{4}$ tested 508 strains belonging to 24 species of dermatophytes against conventional (itraconazole and fluconazole) and some newer antifungal agents like voriconazole and UR-9825, with similar results. This seems to support the fact that incubating for four or seven days does not have a significant effect on the MIC readings.

Nevertheless, our result on terbinafine as the most active agent for example, agrees with the observation from previous authors in other continents and region ${ }^{5,18}$. This antimycotic showed an excellent in vitro potency and broad-spectrum activity against all the tested species. This suggests that terbinafine can be used to treat a majority of dermatophytic infections especially those showing high MIC values on the azoles, such as fluconazole. Although we did not include the newer antifungals such as posaconazole, voriconazole etc in our study, we noticed in literature, their promising antifungal activities. In Nigeria, these antifungals are relatively new and not readily available, affordable and widely used as the ones we have tested. This buttresses our initial observation that most patients with dermatophytoses resort to use of some medicinal plants as a preferred treatment choice apparently due to inability to afford the orthodox drugs ${ }^{14}$.

It will be of interest to state that all isolates used in our study were obtained from patients not previously on any antifungal treatment. Interestingly, there was no record of resistance in our study even though some agents recorded high MIC values than others. From our data, ketoconazole appears to be the next choice in terms of in vitro activity after terbinafine and itraconazole. This information among other things will assist clinicians to monitor trend and be able to choose effective medications for treating patients with dermatophytoses, especially in countries like Nigeria where dermatophytoses have become a public health problem and have remained endemic ${ }^{13}$.

\section{RESUMO}

\section{Teste de susceptibilidade in vitro de dermatófitos isolados de casos pediátricos na Nigéria contra cinco antifúngicos}

Atividades antifúngicas de itraconazole, ketoconazole, fluconazole, terbinafine e griseofulvina foram testadas por métodos de microdiluição em caldo contra 71 isolados de dermatófitos de crianças nigerianas. A maioria das drogas foi muito ativa contra todos os dermatófitos e o MIC 90 variou de 0,03 a $8,0 \mu \mathrm{g} / \mathrm{mL}$. Estes parecem ser os primeiros dados documentados sobre os testes de susceptibilidade antifúngica de isolados de dermatófitos de crianças nigerianas.

\section{REFERENCES}

1. BARRY, A.L.; PFALLER, M.A.; BROWN, S.D. et al. - Quality control limits of broth microdilution susceptibility tests of ten antifungal agents. J. clin. Microbiol., 33: 3457-3459, 2000.
2. EKANEM, L.S \& GUGNANI, H.C - Etiology of dermatophytoses in Cross-River State of Nigeria. Mykosen, 30: 493-498, 1987.

3. FAVRE, B.; HOFBAUER, B.; HILDERING, K.S. \& RYDER, N.S. - Comparison of in vitro activities of 17 antifungal drugs against a panel of 20 dermatophytes by using microdilution assay. J. clin. Microbiol., 41: 4817-4819, 2003.

4. FERNÁNDEZ-TORRES, B.; CABANES, F.J.; ALFONSO, J. et al. - Collaborative evaluation of optimal antifungal susceptibility testing condition for dermatophytes. J. clin. Microbiol., 40: 3999-4003, 2002.

5. FERNANDEZ-TORRES, B.; CARRILLO, A.J.; MARTÍN, E. et al. - In vitro activities of 10 antifungal drugs against 508 dermatophyte strains. Antimicrob. Agents Chemother., 45: 2524-2528, 2001.

6. FERNÁNDEZ-TORRES, B.; INZA, I. \& GUARRO, J. - In vitro activities of the new antifungal drug eberconazole and three other topical agents against 200 strains of dermatophytes. J. clin. Microbiol., 41: 5209-5211, 2003.

7. GHANNOUM, M.A.; CHATURVEDI, V.; ESPINEL-INGROFF, A. et al. - Intra- and interlaboratory study of a method for testing the antifungal susceptibilities of dermatophytes. J. clin.Microbiol., 42: 2977-2979, 2004.

8. GUGNANI, H.C. \& NJOKU-OBI, A.N.U - Tinea capitis in school children in eastern Nigeria. Mykosen, 29: 132-140, 1986.

9. GUPTA, A.K. \& DEL ROSSO, J.Q. - An evaluation of intermittent therapies used to treat onychomycosis and other dermatomycoses with the oral antifungal agents. Int. J. Derm., 39: 401-411, 2000.

10. GUPTA, A.K.; KOHLI, Y. \& BATRA, R. - In vitro activities of posaconazole, ravuconazole, terbinafine, itraconazole and fluconazole against dermatophyte, yeast and non-dermatophyte species. Med. Mycol., 43: 179-185, 2005.

11. NATIONAL COMMITTEE FOR CLINICAL LABORATORY STANDARDS Reference method for broth dilution antifungal susceptibility testing of conidiumforming filamentous fungi. Proposed standard Document no. M38-P. Wayne, NCCLS, 1998.

12. NORRIS, H.A.; ELEWSKI, B.E \& GHANNOUM, M.A. - Optimal growth conditions for the determination of the antifungal susceptibility of the three species of dermatophytes with use of a microdilution method. J. Amer. Acad. Derm, 40(6 pt. 2): S9-S13, 1999.

13. NWEZE, E.I. - Etiology of dermatophytoses amongst children in northeastern Nigeria. Med. Mycol., 39: 181-184, 2001.

14. NWEZE, E.I. \& OKAFOR, J.I. - Prevalence of dermatophytic fungal infections in children: a recent study in Anambra State, Nigeria. Mycopathologia, 160: 239-243, 2005.

15. PFALLER, M.A.; DIEKEMA, D.J.; MESSER, S.A. et al. - Activities of fluconazole and voriconazole against 1,586 recent clinical isolates of Candida species determined by broth microdilution, disk diffusion, and Etest methods: report from the ARTEMIS global antifungal susceptibility program, 2001. J. clin. Microbiol., 41: 1440-1446, 2003.

16. REX, J.H.; PFALLER, M.A.; WALSH, T.J. et al. - Antifungal susceptibility testing: practical aspects and current challenges. Clin. Microbiol. Rev., 14: 643-658, 2001.

17. ROBERTS, D.T. - Onychomycosis: current treatment and future challenges. Brit. J. Derm., 141(suppl. 56): 1-4, 1999.

18. SANTOS, D.A. \& HAMADA, J.S. - Evaluation of broth microdilution antifungal susceptibility testing conditions for Trichophyton rubrum. J. clin. Microbiol., 43: 1917-1920, 2005

Received: 5 July 2006

Accepted: 1 March 2007 